UCRL-JC-130314

PREPRINT

\title{
High intensity direct third harmonic generation in BBO
}

\author{
P. S. Banks, M. D. Feit, and M. D. Perry
}

This paper was prepared for and presented at the

Nonlinear Optics ' 98

Kauai, HI

August 10-14, 1998

February 23, 1998

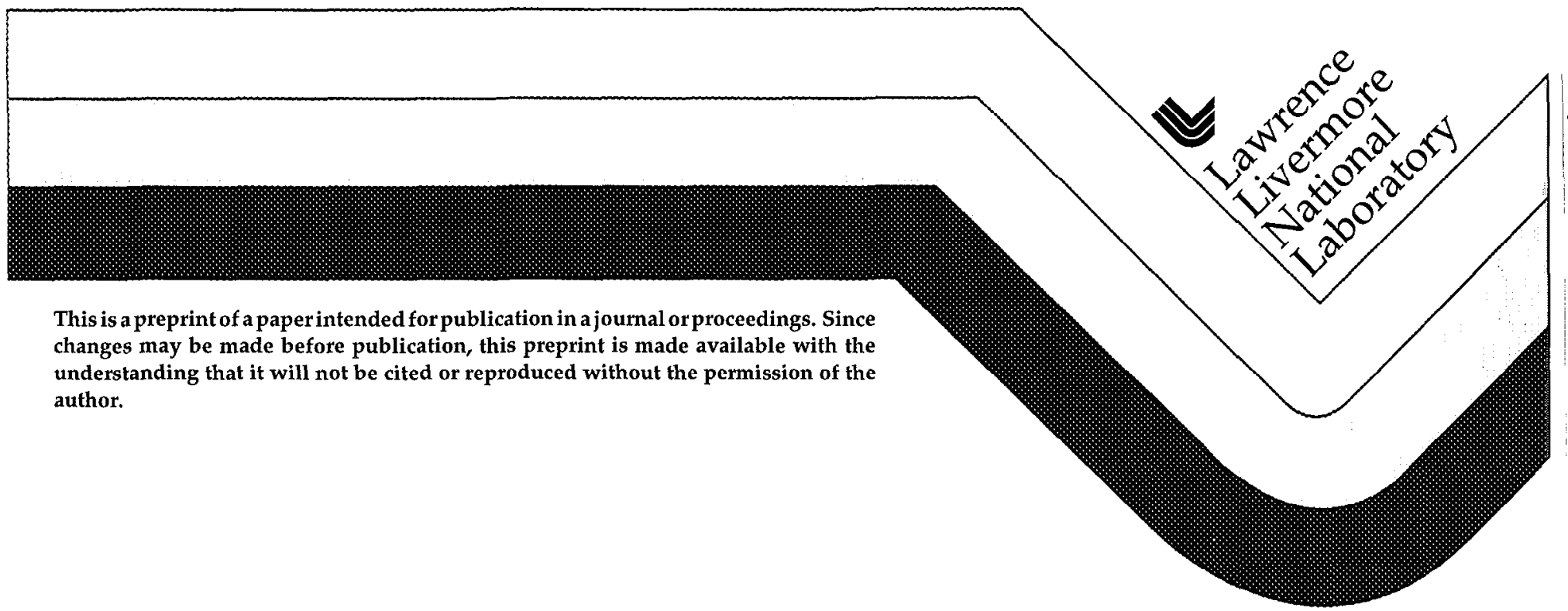




\section{DISCLAIMER}

This document was prepared as an account of work sponsored by an agency of the United States Government. Neither the United States Government nor the University of California nor any of their employees, makes any warranty, express or implied, or assumes any legal liability or responsibility for the accuracy, completeness, or usefulness of any information, apparatus, product, or process disclosed, or represents that its use would not infringe privately owned rights. Reference herein to any specific commercial product, process, or service by trade name, trademark, manufacturer, or otherwise, does not necessarily constitute or imply its endorsement, recommendation, or favoring by the United States Government or the University of California. The views and opinions of authors expressed herein do not necessarily state or reflect those of the United States Government or the University of California, and shall not be used for advertising or product endorsement purposes 


\title{
High intensity direct third harmonic generation in BBO
}

\author{
P. S. Banks, M. D. Feit, and M. D. Perry \\ Laser Program, Lawrence Livermore National Laboratory \\ P. O. Box 808, L-439, Livermore, CA 94550
}

510-422-3125, fax: 510-422-5537

The azimuthal dependence of second- and third-order coupling are used to measure the relative contributions of each to direct third harmonic generation with efficiencies up to $6 \%$.

The values of $\chi_{\mathrm{ij}}^{(3)}$ are measured.

This work was performed under the auspices of the U.S. DOE by LLNL under contract No. W-7405-Eng-48. 


\title{
High intensity direct third harmonic generation in BBO
}

\author{
P. S. Banks, M. D. Feit, and M. D. Perry \\ Laser Program, Lawrence Livermore National Laboratory \\ P. O. Box 808, L-439, Livermore, CA 94550
}

Generation of the third harmonic (THG) in a single process is an idea that has been around since the inception of nonlinear optics. ${ }^{1-3}$ However, since the process $\omega+\omega+\omega \rightarrow 3 \omega$ is governed by the third order nonlinear electric susceptibility $\chi^{(3)}$, the efficiency of such an interaction has been very low. To this date, the high intensities needed to drive this process has confined most research into higher order harmonic conversion to highly focused beams in gases or liquids. Recently, the increasing number of terawatt-class chirped-pulse amplification (CPA) lasers (and beyond) in recent years has made it possible to achieve very high intensities $\left(>100 \mathrm{GW} / \mathrm{cm}^{2}\right)$ in collimated beams in solids without damaging material.

Efficiencies for THG in solids have been limited to less than a percent with the highest conversion achieved using BBO. It has been suggested that unphasematched second-order processes can contribute significantly to $\mathrm{THG}^{4-6}$ similar to the use of cascaded secondorder processes giving rise to an effective nonlinear refractive index. ${ }^{7,8}$ However, experimental uncertainties in efforts to assess this contribution by measuring conversion efficiency ${ }^{6,9}$ were too large to determine the relative contributions of the several processes. We were able to vary the azimuthal angle $\phi$ in $\mathrm{BBO}$ and measured directly the relative contributions of $\chi^{(2)}$ and $\chi^{(3)}$ to THG in BBO for both Type I and Type II phasematching. Consequently, we were also able to determine relative values for the tensor element $\chi_{10}^{(3)}, \chi_{11}^{(3)}$, and $\chi_{16}^{(3)}$, and have achieved conversion efficienies to the third harmonic (355 nm) of up to $6 \%$.

It has been shown ${ }^{4-6}$ that because the fundamental and third harmonic waves are in phase, $\Delta k=0$, regardless of the intervening processes, it is possible to have energy transfer to the third harmonic by two cascaded second order processes. First the second harmonic is generated (SHG) and then is summed with the fundamental to generate the third harmonic (SFG). This can occur efficiently even though neither the SHG nor the SFG process are phasematched.

Using the fact that $\mathrm{BBO}$ is a uniaxial crystal and so direct THG should be independent of the azimuthal angle $\phi$, we varied $\phi$ for a $3 \mathrm{~mm}$ long $\mathrm{BBO}$ crystal with a sol-gel AR coating to eliminate angular variations in surface reflectivity. Because the phasematching angles for Type I and Type II THG at the incident wavelength of $1053 \mathrm{~nm}$, we wcre ablc to measure the THG efficiency for both Type I (ooo $\left.\rightarrow e, \theta_{m}=37.7^{\circ}\right)$ and Type II (ooe $\rightarrow e$, $\left.\theta_{m}=47.1^{\circ}\right)$ configurations using the same crystal of BBO (3 mm in length). The effective nonlinear susceptibility $C_{\text {eff }}=\chi_{\text {eff }} / 4$ (including both second and third order effects) for Type I phasematching is

$$
C_{\text {eff }}=A \sin 6 \phi+\left(\sin \theta_{m} C_{10}-B\right) \cos 3 \phi
$$

with

$$
A=\frac{\omega}{2 c} d_{22}^{2}\left[\frac{\cos \theta_{m}}{n_{2 o} \Delta k_{o o e}^{\mathrm{SFG}}}-\frac{\cos ^{3} \theta_{m}}{n_{2 e} \Delta k_{\text {eoe }}^{\mathrm{SFG}}}\right]=77.92 \mathrm{pm}^{2} / \mathrm{V}^{2}, \text { and }
$$



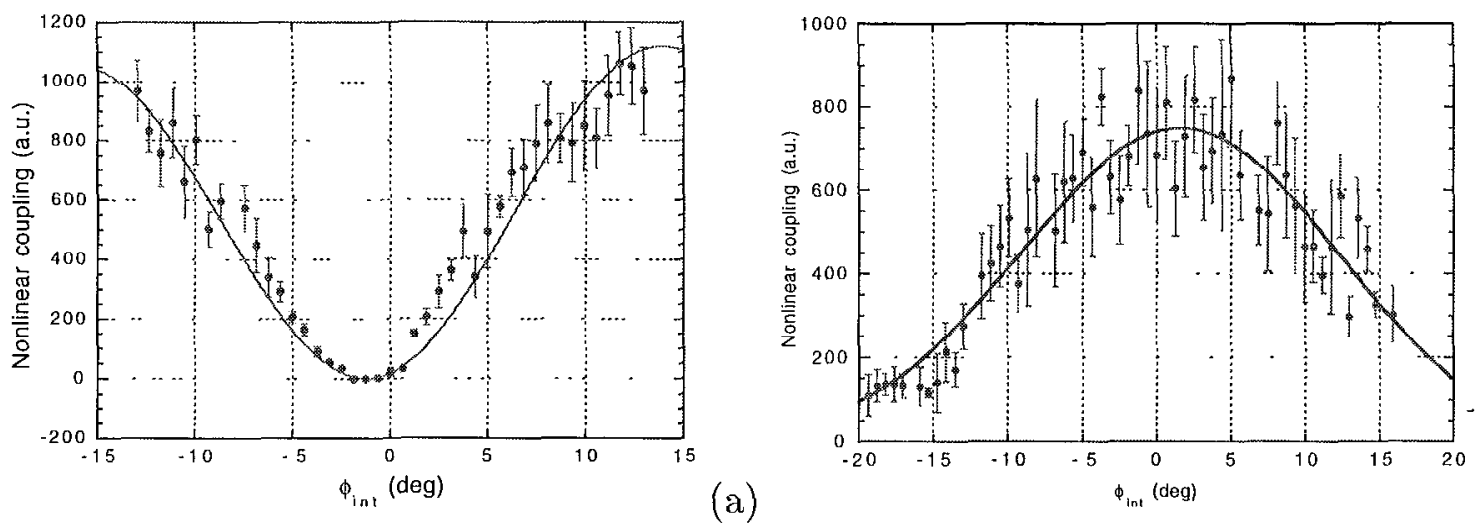

Figure 1: Effective nonlinear coupling for internal azimuthal angle $\phi_{\text {int }}$ for (a) Type I and (b) Type II phasematching.

$$
B=\frac{\omega}{2 c} d_{22} d_{15}\left[-\frac{\sin \theta_{m}}{n_{2 o} \Delta k_{\text {ooe }}^{\mathrm{SFG}}}-\frac{\cos ^{2} \theta_{m} \sin \theta_{m}}{n_{2 e} \Delta k_{\text {eoe }}^{\mathrm{SFG}}}\right]=-8.76 \mathrm{pm}^{2} / \mathrm{V}^{2}
$$

The values used for $d_{22}$ and $d_{15}$ for $\mathrm{BBO}$ were $2.2 \mathrm{pm} / \mathrm{V}$ and $.16 \mathrm{pm} / \mathrm{V},{ }^{10}$ respectively. The nonlinear coupling for Type I THG as a function of $\phi$ is shown in Fig. 1. Fitting Eq. (1) to the measured data gives a value for $C_{10}=\chi_{10}^{(3)} / 4$ of $1.1 \times 10^{-23} \mathrm{~m}^{2} / \mathrm{V}^{2}$. This compares to an effective value for the cascaded second order coupling of $8 \times 10^{-23} \mathrm{~m}^{2} / \mathrm{V}^{2}$.

Similarly, for Type II phasematching, the effective nonlinear coupling is given by (neglecting all terms proportional to $d_{15}^{2}$ )

$$
\begin{aligned}
C_{\text {eff }}= & A \cos ^{2} 3 \phi+B \sin ^{2} 3 \phi \\
& +\sin 3 \phi\left[D+E d_{33}+3 C_{10} \sin 2 \theta_{m}\right] \\
& +F d_{33}+3\left[\frac{C_{11}}{3} \cos ^{2} \theta_{m}+C_{16} \sin ^{2} \theta_{m}\right]
\end{aligned}
$$

where

$$
\begin{aligned}
A & =\frac{2 \pi}{\lambda_{2 \omega_{0}}}\left[2 \frac{\cos ^{4} \theta_{m}}{n_{4} \Delta k_{5}}-\frac{\cos ^{2} \theta_{m}}{n_{3} \Delta k_{8}}\right] d_{22}^{2}=19.9 \mathrm{pm}^{2} / \mathrm{V}^{2}, \\
B & =\frac{2 \pi}{\lambda_{2 \omega_{0}}}\left[2 \frac{\cos ^{2} \theta_{m}}{n_{3} \Delta k_{7}}-\frac{\cos ^{4} \theta_{m}}{n_{4} \Delta k_{6}}\right] d_{22}^{2}=-21.8 \mathrm{pm}^{2} / \mathrm{V}^{2}, \\
D & =-2 \frac{2 \pi}{\lambda_{2 \omega_{0}}}\left[\frac{\sin \theta_{m} \cos ^{3} \theta_{m}}{n_{4} \Delta k_{6}}+\frac{\sin 2 \theta_{m}}{n_{3} \Delta k_{7}}\right] d_{22} d_{15}=2.0 \mathrm{pm}^{2} / \mathrm{V}^{2}, \\
E & =-\frac{2 \pi}{\lambda_{2 \omega_{0}}} \frac{\sin ^{3} \theta_{m} \cos \theta_{m}}{n_{4} \Delta k_{6}} d_{22}=-2.6 \mathrm{pm} / \mathrm{V}, \text { and } \\
F & =\frac{2 \pi}{\lambda_{2 \omega_{0}}} \frac{\sin ^{4} \theta_{m}}{n_{4} \Delta k_{6}} d_{15}=.20 \mathrm{pm} / \mathrm{V} .
\end{aligned}
$$

The value for $C_{10}$ can be used from the Type I measurements since this is the same crystal. However, $d_{33}$ is unknown and must be used as a parameter for the fit. We obtain a value for 

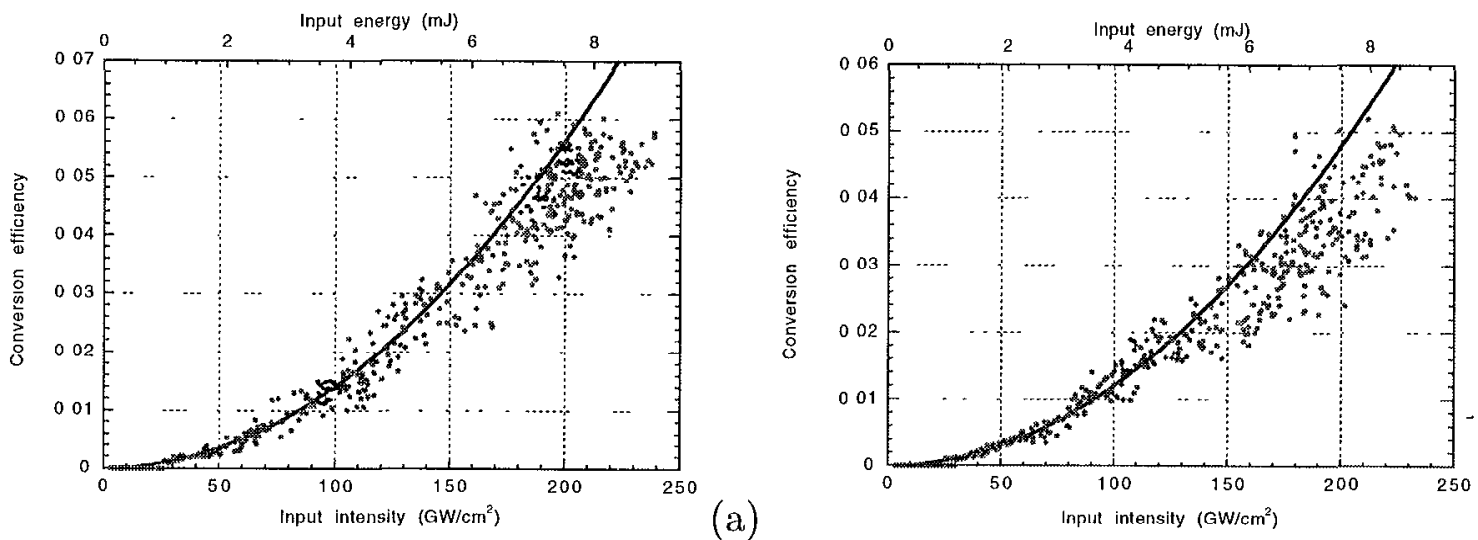

Figure 2: Energy output from single BBO crystal at $351 \mathrm{~nm}$ along with cubic fit to low drive points. (a) Type I phasematching with $\phi_{\text {int }}=-15^{\circ}$. (b) Type II phasematching $\left(\phi_{\text {int }}=0\right)$.

$C_{11} \cos ^{2} \theta_{m}+C_{16} \sin ^{2} \theta_{m}$ of $1 \times 10^{-23} \mathrm{~m}^{2} / \mathrm{V}^{2}$ with $d_{33}=1.7 \mathrm{pm} / \mathrm{V}$. With this method, there is no way to further separate the contributions of $C_{11}$ and $C_{16}$.

For both Type I and Type II processes, it is evident that the cascaded, second-order interactions can contribute strongly to THG. In fact, for Type I phasematching, there are configurations where it dominates over the expected third-order coupling and can lead to efficient generation of the third harmonic. major contribution to the THG observed is the cascaded process, not the third order process. Finally, Figs. 2(a) and 2(b) show conversion efficiency to the third harmonic $(355 \mathrm{~nm})$ from the fundamental $(1055 \mathrm{~nm})$ for 350 fs pulses. In both cases, efficiencies of $5-6 \%$ were achieved with saturation beginning to have an effect above $200 \mathrm{GW} / \mathrm{cm}^{2}$.

\section{References}

1. R. W. Terhune, P. D. Maker, and C. M. Savage, Appl. Phys. Lett. 2, 54 (1963).

2. P. D. Maker and R. W. Terhune, Phys. Rev. 137, A801 (1965).

3. R. C. Eckardt and C. H. Lee, Appl. Phys. Lett. 15, 425 (1969).

4. C. Flytzanis and N. Bloembergen, Prog. Quant. Electr. 4, 271 (1976).

5. G. R. Meredith, J. Chem. Phys. 77, 5863 (1982).

6. P. Qiu and A. Penzkofer, Appl. Phys. B 45, 225 (1988).

7. F. Hache, A. Zeboulon, G. Gallot, and G. M. Gale, Opt. Lett. 20, 1556 (1995).

8. R. DeSalvo, D. J. Hagan, M. Sheik-Bahae, G. Stegeman, and E. W. Van Stryland, Opt. Lett. 17, 28 (1992).

9. I. V. Tomov, B. Van Wonterghem, and P. M. Rentzepis, Appl. Opt. 31, 4172 (1992).

10. Y. X. Fan, R. C. Eckardt, R. L. Byer, C. Chen, A. D. Jiang, IEEE J. Quantum Electron. QE-25, 1196 (1986). 


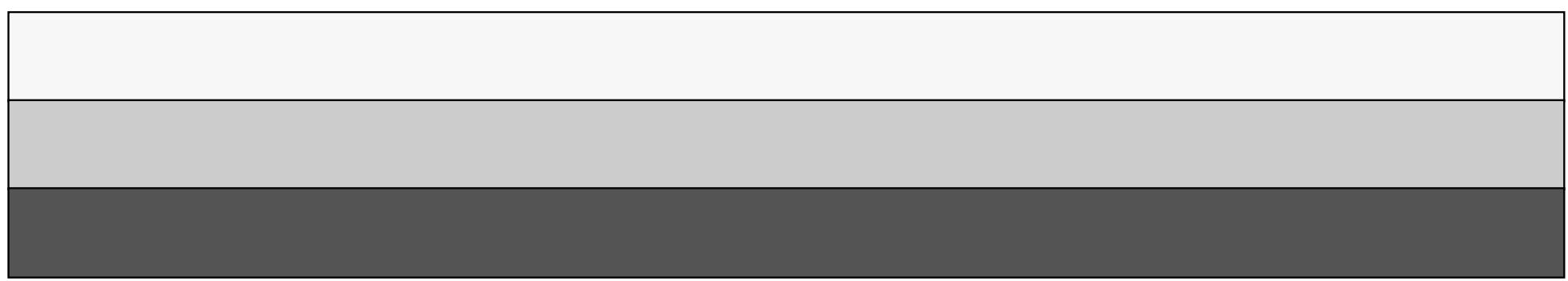

